\title{
Design and Implementation of Digital Attendance System using OTP Encryption
}

\author{
Tonni Das Jui
}

\author{
S. M. Kamal Hussain Shahi
}

S. M. Musharaf Hussain

\begin{abstract}
The research explored the opportunities to save times while conducting student attendance in universities and colleges. The research also emphasizes on minimizing proxy attendance among students. In order to maintain a sophisticated attendance system we have designed and developed methodology which has unique features that will allow lecturers and teachers to spend more productive hours with their students. This research mainly focuses on smart attendance system which allows classroom authorities to save valuable hours. To increase student's attendance by eliminating proxy attendance also a vital focus area of this very research. Using a mobile and web application development platform ensures security and effectiveness to collect students attendance data and manage storage for it without single paperwork. Unique identity of students for protecting valid student's attendance from being adulterated by proxy or fake students is provided to both users end (teachers end and students end). The availability of smart devices may make sure of utilizing campus network.
\end{abstract}

\section{General Terms}

Timed encryption method, decryption on teachers end

\section{Keywords}

Attendance, Student's-end, Teacher's-end, Smart-devices, Network, Time saving, OTP

\section{INTRODUCTION}

Manual participation taking and report era has its impediments. In modern era, the number of students per class has also increased drastically. To cope up with technological smartness, every colleges and universities has setup their own campus network. Most of the students have smart devices such as mobile, tablet, laptop etc. Therefore, it is high time to utilize the campus network and smart devices to create a futuristic attendance system. Roll calling and manual attendance program is a failure for taking part for a lecture, a meeting, etc. Time wastage over student answers, paper waste, etc. is the drawback of a manual attendance program. With regards to rapid changes with the use of IOT, there are many tools, Technologies and systems have been produced and invented. In the modern world, time is short so if there are many processes takes place at same time within a place there is a need for integration of all the processes, creation of paperless environment also ensures efficient task management. The purpose to having a mobile based system is very easy to use for all others. There will be different level of users in this application. The Digital Attendance system is a media communication system that used to monitor the attendance of a student within the class hours. Attendance management is important to every single educational institution. Educational organizations will have to keep track of students to maximize their performance. Managing student's attendance during lecture periods has become a difficult challenge. The ability to compute the attendance percentage becomes a major task as manual computation produce errors and waste lot of times. For the stated reason, efficient android application for the attendance management system is designed to track student's activity in the class. Online attendance generation system using a database will erase paperwork and make this process saving time and cost both.

\section{LITERATURE REVIEW}

The word 'Digital System' refers to the collection of discrete values. To get rid of tons of paper work, Digital attendance system is currently being used, as digital information is easy to process and easy to access compared with manual data. As far as we are concerned, the long journey has started before twentieth century. To mention one of many, automated student attendance system using Fingerprint Recognition was developed. To effectively manage attendance of students, a fingerprint recognition based identification system is used for biometric identification [1]. In other research, attendance is marked after student identification. Fingerprint recognition based identification system is used for student identification. Fingerprints are known as the easiest and fastest means of biometric authentication [2]. Almost same mechanism was used later version of advance wireless attendance system using fingerprint. They attached devices like computer or mobile with a scanner to verify students or employees identification so that fraud activities can be minimized [3]. The idea of a manual card slot or hole to insert the timesheet employees and an analog clock showing the current time for the employees to insert the card into the slot is what will be printed on the timesheet, was introduces and implemented on a an android device [4]. Hosting system is introduced where the host computer may additionally be connected, along with a plurality of other host computers, to a central computer capable of retrieving and analyzing information from all host computers [5]. Another system was developed using encryption methodology and implemented using Java programming language to operate at varying threshold value. The developed system's performance was evaluated using False Reject Rate (FRR) and False Accept Rate (FAR) as performance metrics [6]. In 2018 another research was focused. This share proves employee attendance and is saved in the employee's record with employee's ID. Finally, at the end of the payment round, in this case assumed to be a month, the iAttend scheme calculates all shares to compute the total attendance record of each employee for the month [7].

\section{PROPOSED METHODOLOGY}

To start the process the user (teacher/lecturer) has to login to the system. After that the user select the class/batch that the user going to conduct. An OTP (One time password) will be generated automatically once class/batch selected. At the same time this OTP will be sent to the database temporarily and students will receive an attendance requests in their registered application ID. 


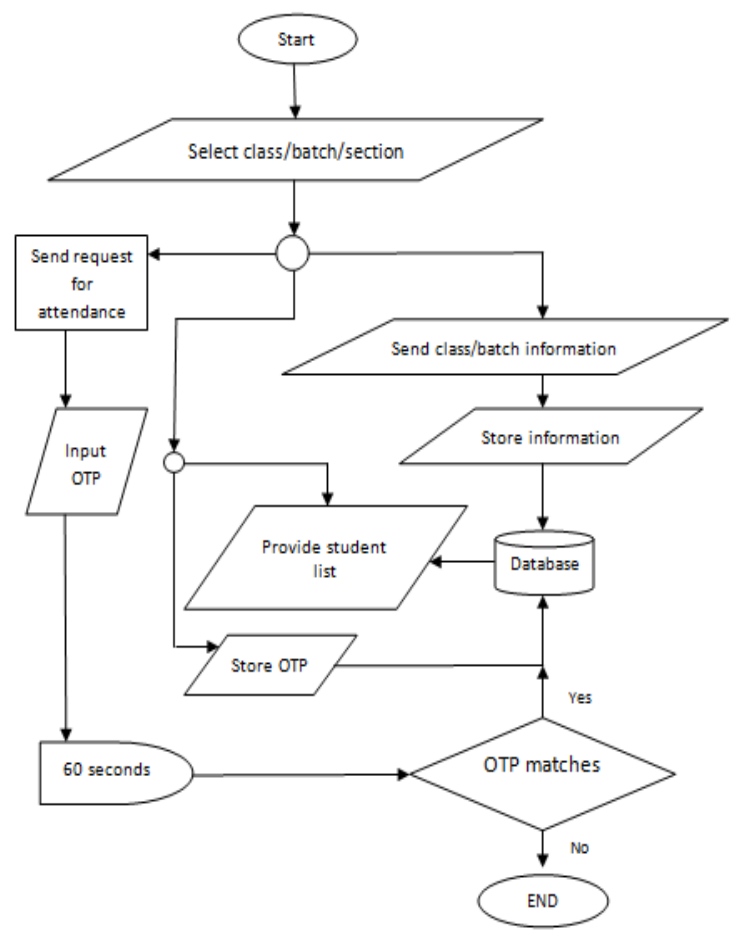

Fig 1: Teacher and student both from their end

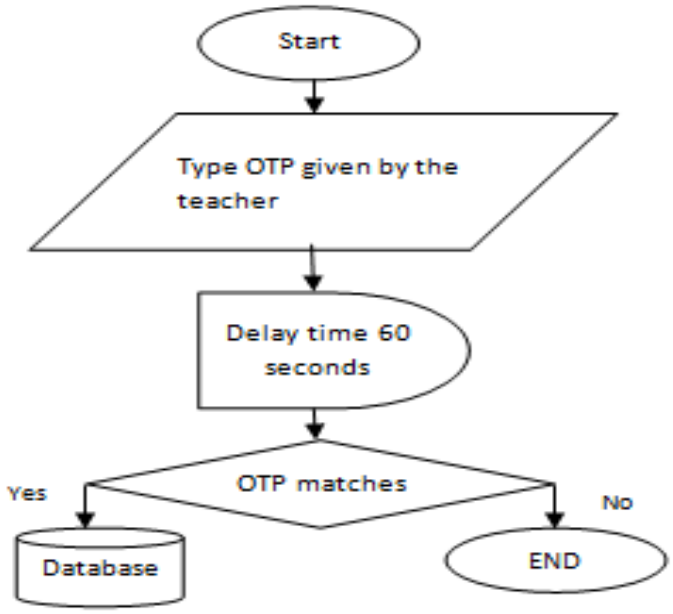

Fig 2: Students giving attendance

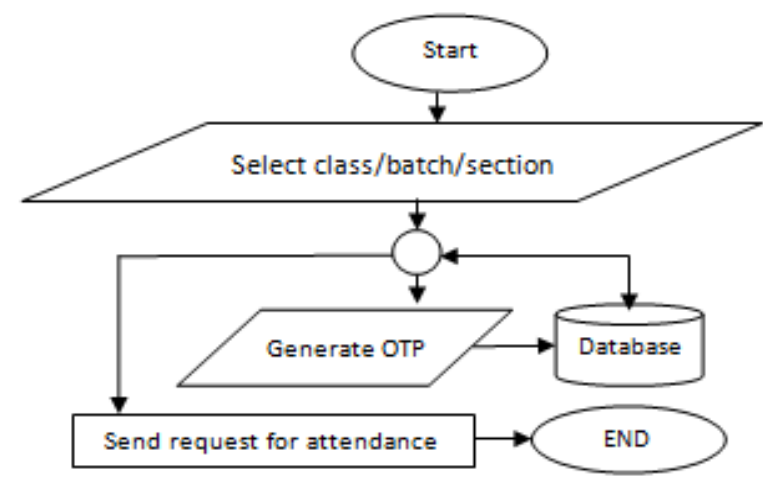

Fig. 3: Teacher creating password encrypted attendance sheet

Now the students have 60 seconds to open window to insert the OTP. The 60 seconds delay instead of unlimited time delay is set intentionally to prevent student's proxy. All the data's input by students will be sent to database to match against primary generated OTP. The system will count the students attendance if he/her input data matches with primary OTP and if it does not match all the data than it will not count the attendance. Surely the students, who do not know the temporary one time valid password that is created by the corresponding faculty member, will not be able to insert their attendance. Then, the process will be end. The process has been described in the fig. 1, fig. 2 and fig. 3 .

\section{IMPLEMENTATION}

In this application there are two sections.

\section{Teacher Section}

\section{Student Section}

There are few functioning features on teacher Section.

Teacher Login: For this application a teacher have to login. And for login option required information (Teacher ID and Password) needed.

Select Batch \& Section: In the select batch and section are teacher will select batch and section to take attendances.

Student List: In the student list the teacher will able to see the students profile who are registered.

Send Request: When are teacher will click send button OTP will show in his/her display and send request for attendance.

Student Section contains a portal for students to log in and provide the faculty member with their attendance.

Student Registration: At first a student has to register. For the registration student need the required data (Full name, Student ID, Birth of date, Password, Batch and Section)

Student Login: For the Login section a student has to provide his/her student id and password.

Student Profile: After login a student can see his/her profile in details such as (Full name, Student ID, Birth of date, Batch and Section).

Attendance: After allow to take attendance the student able to open this attendance activity. Then teacher will provide OTP number to the student and entering this OTP.

\subsection{Teacher Section:}

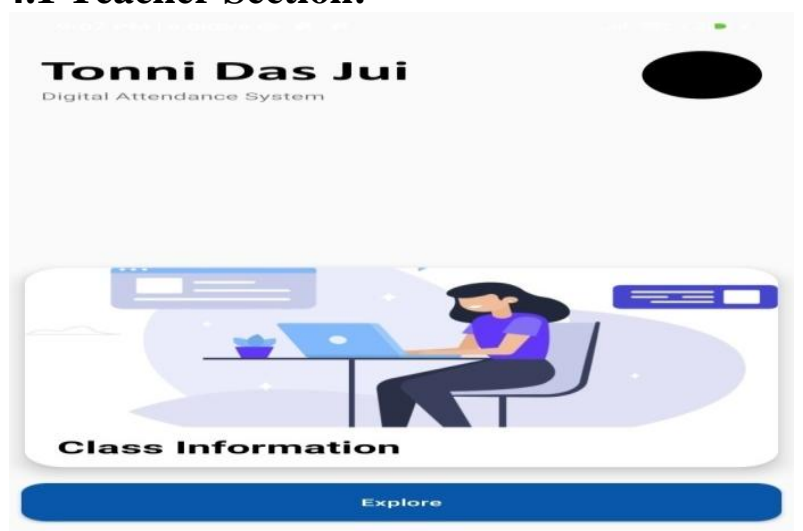

Fig 4.1.1: Class Information 
In the fig: 4.1.1, there is a visual representation of the implementation of digital attendance system from teacher's end. This is a Class information activity. From the teacher's end the students list can be found which is also represented on fig: 4.1.3. Teacher or lecturer will register his or her allocated classes on this activity. On other hand, teacher or lecturer will see his/her class information anytime. When he/she click in explore button he/she can see the details about batch and sections and can delete any information he/she wants. (Fig: 4.1.2)

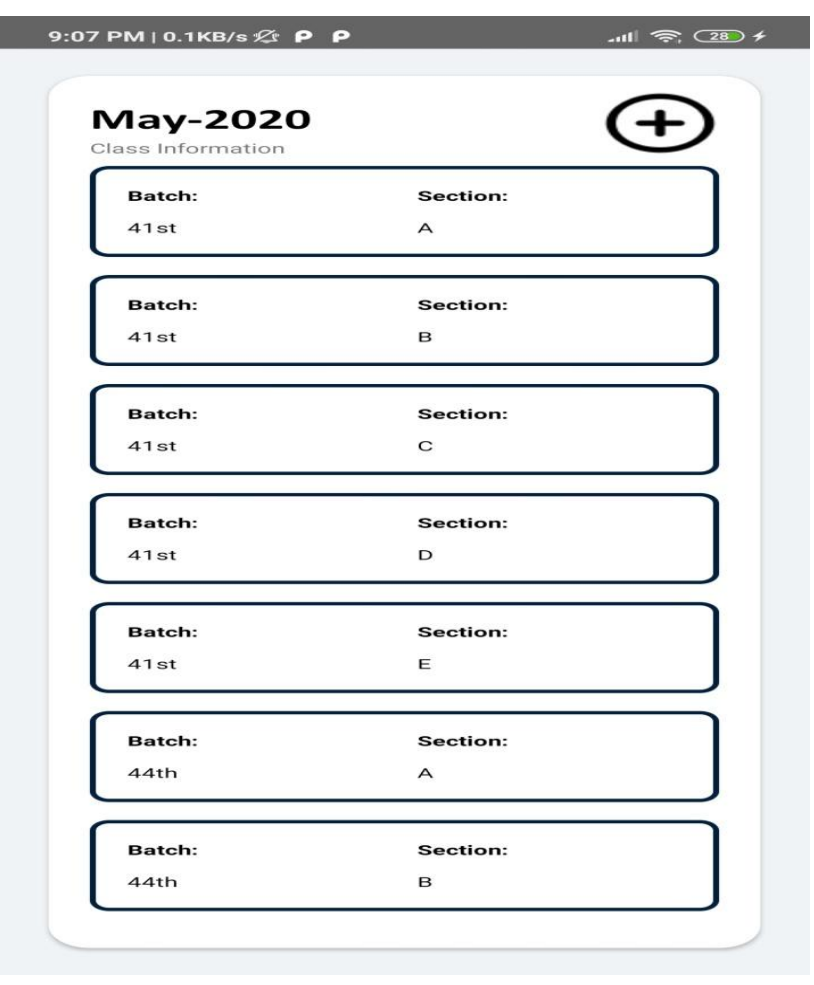

Fig 4.1.2: Class Information Details

\section{Tonni Das Jui}

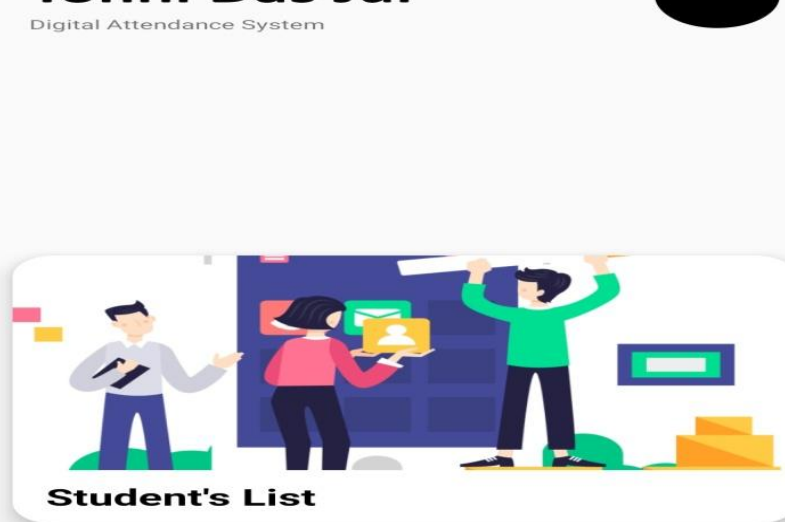

$$
\text { Explore }
$$

Fig 4.1.3: Student's list
When the teacher or lecturer wants to see student list he/she will click this explore button. After that Batch and Section should be selected to see the whole list. (Fig: 4.1.4)

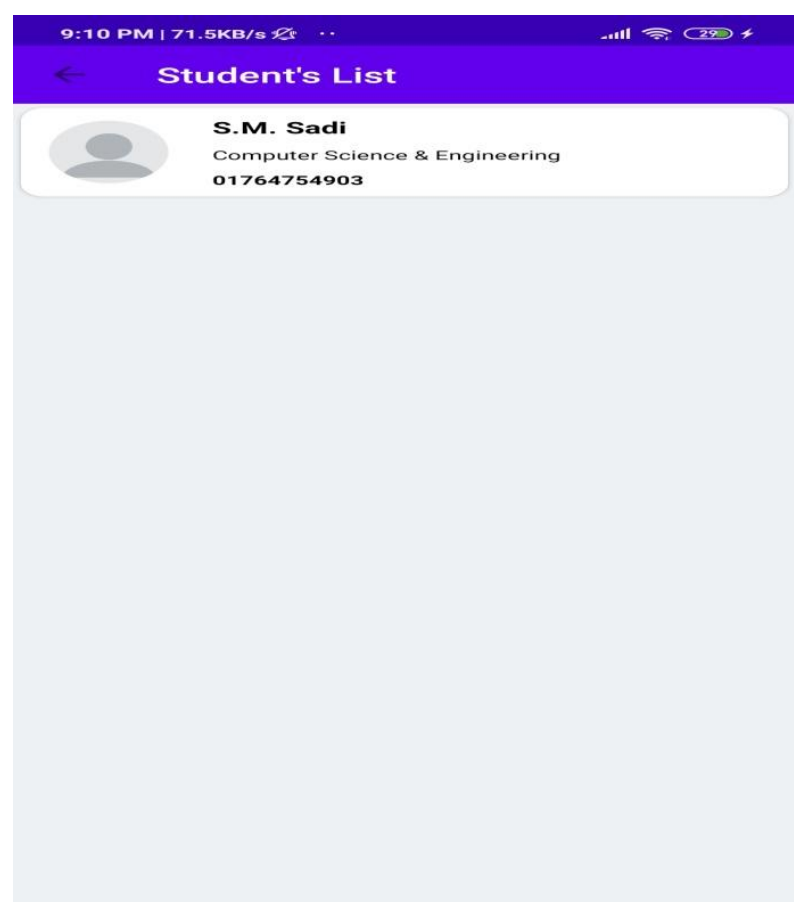

Fig 4.1.4: Student's list Details

Tonni Das Jui

Digital Attendance System

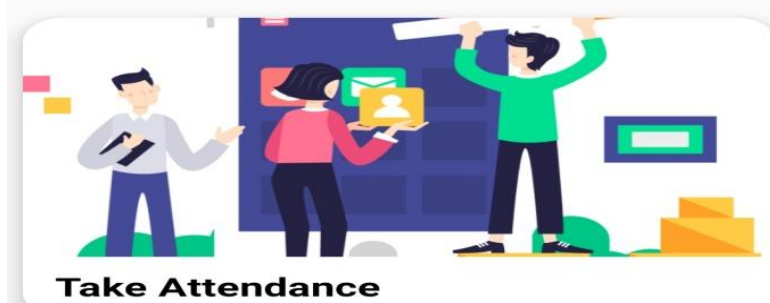

Explore

\section{Fig 4.1.5 Take attendance}

The teacher/lecturer click this explore button for taking attendance and popup activity will open where teacher/lecturer has to select his/her batch, section, course name and code (Fig 4.1.6). Then confirmation window will pop-up (Fig 4.1.7), if the information are correct he/she select confirm. An OTP will generate right after that. (Fig: 4.1.8) 


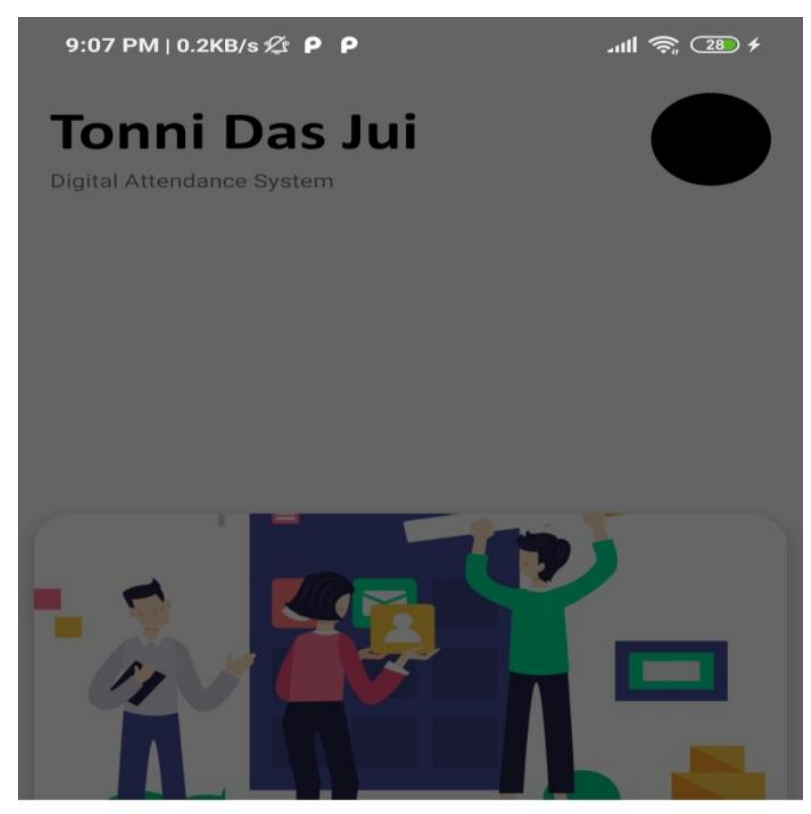

\section{Take Attendance}

Select Batch \& Section:

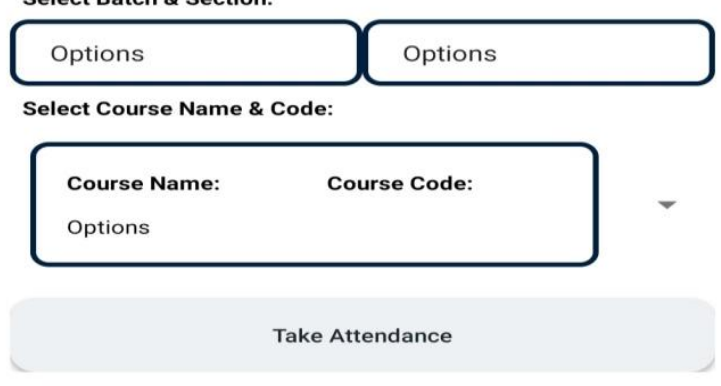

Fig 4.1.6 Select Batch \& Section for take attendance

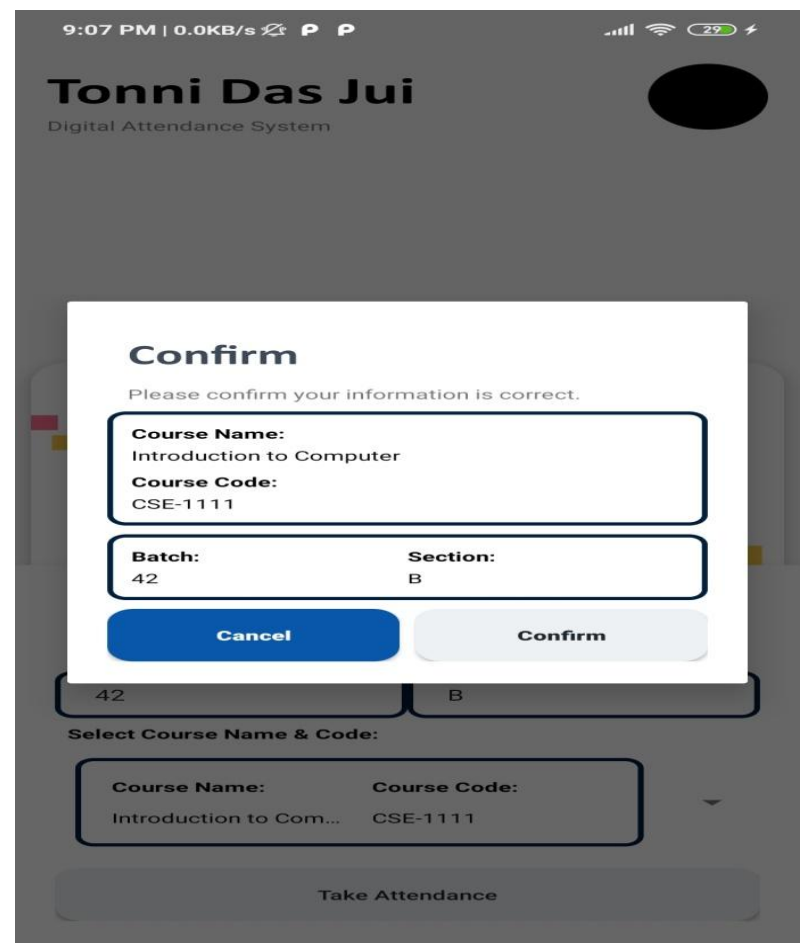

Fig 4.1.7 Confirm pop-up window

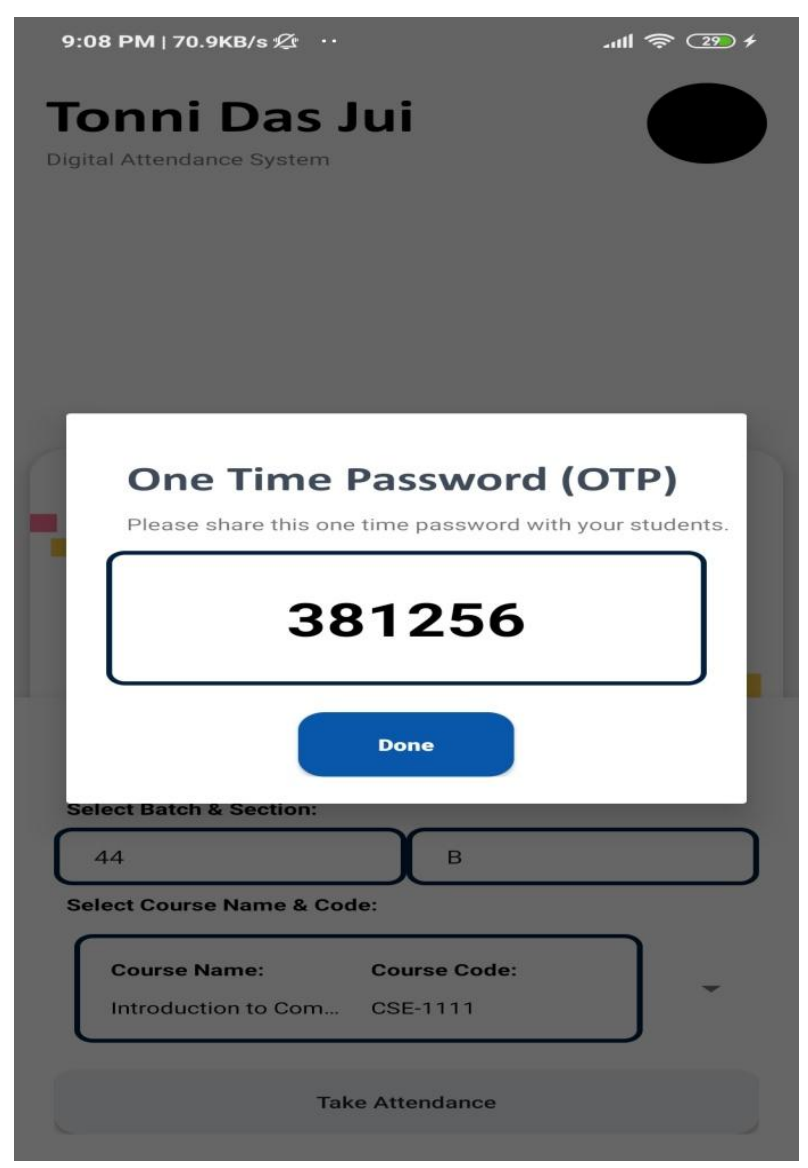

Fig 4.1.8 Generate OTP

Tonni Das Jui

Digital Attendance System
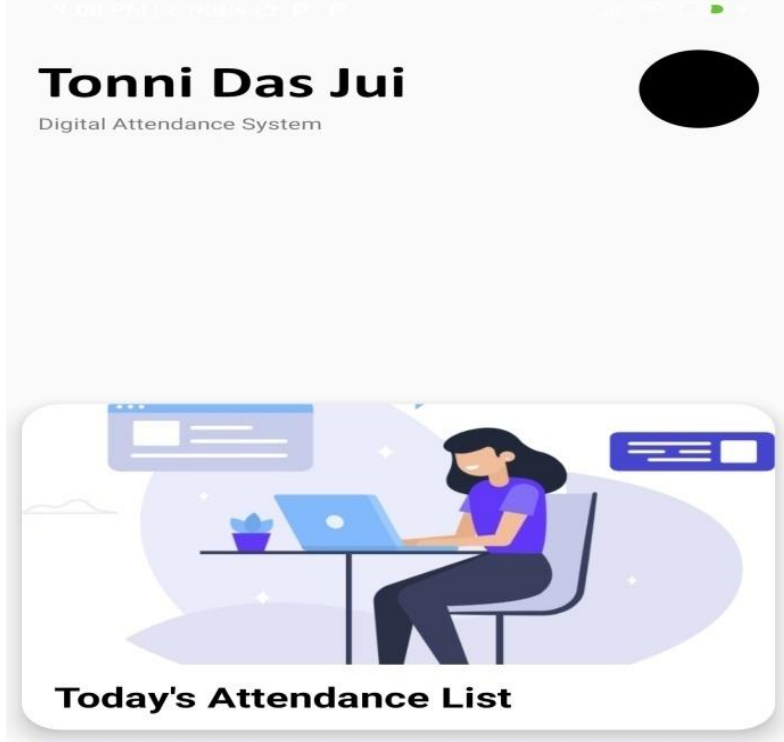

Explore

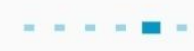

Fig 4.1.9 Today's attendance 
To see today's attendance list teacher/lecturer will click explore button then select batch and section. In this section he/she can identify the number of absent students. (Fig: 4.1.9)

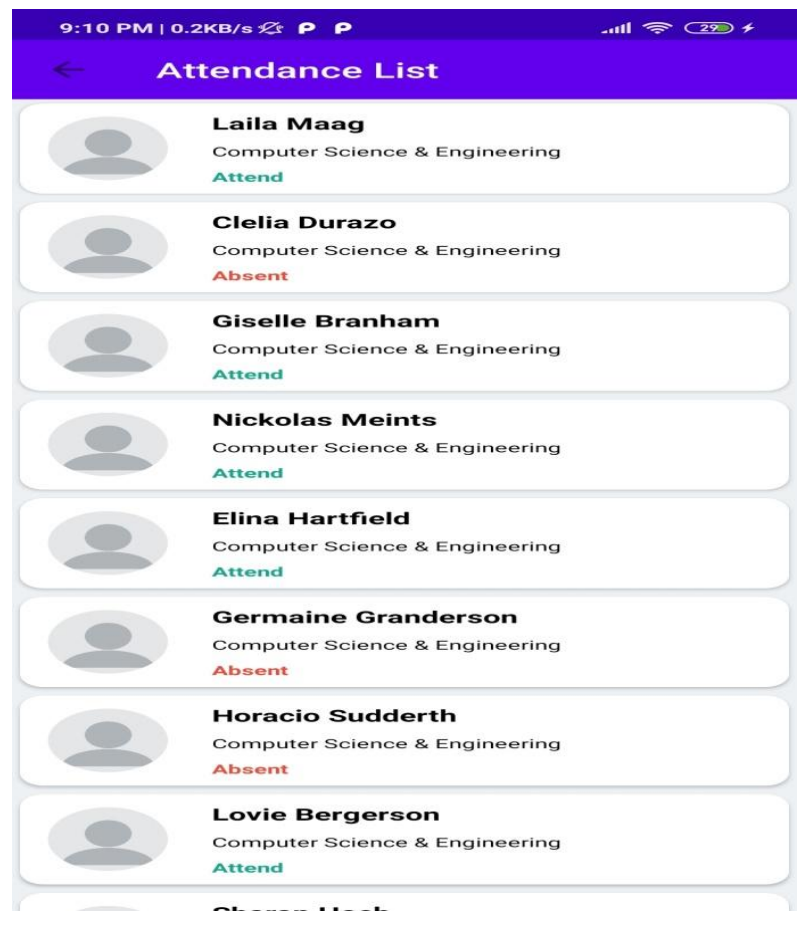

Fig 4.1.10 Today's attendance list

\subsection{Student Section}

\section{$9.56 \mathrm{PM} / 3 . \mathrm{KB} / \mathrm{s}$ \&}

\section{S.M. Sadi}

Disital Attendance System

\section{Profile}

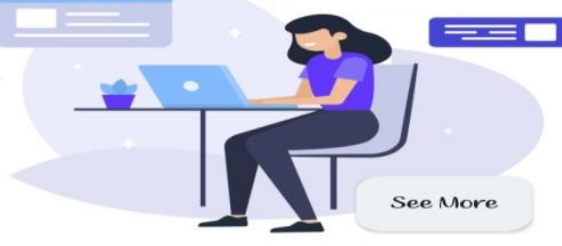

Fig 4.2.1 Student Profile

This is student profile section, they can see their details information like name, email, batch, section, student id and also they can edit their profile information. (Fig: 4.2.1). In the student profile segment, students are allowed to keep basic data information which can be cross-checked if any error occurrence takes place [8]. The detailed information about the classroom should be arranged on the teacher's end [9].

9.57 PMI OAKB/S 2:S

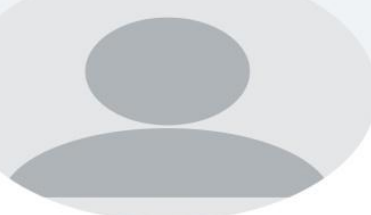

S.M. Sadi

Department

Computer Science \&: Engineering

Student Id:

1712020087

Batch:

44

Section:

B

Email:

sadi@gmail.com

Mobile:

n1764754903

Fig 4.2.2 Student Details Information

\section{S.M. Sadi}

Digital Attendance System

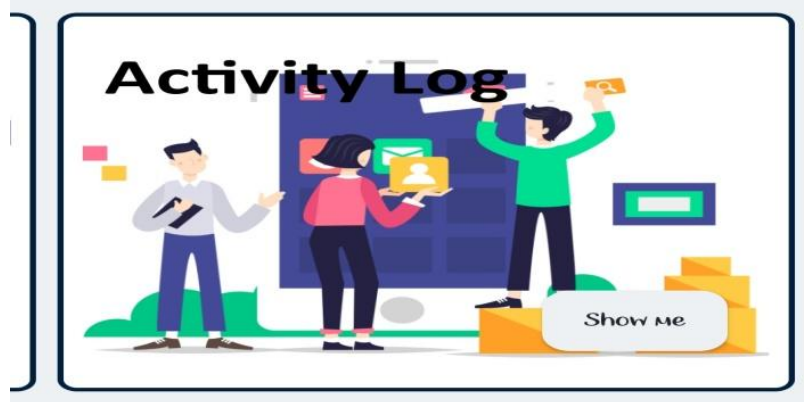

Fig 4.2.3 Student Activity Log 
This is activity log where students can see which class they attended and which they didn't. (Fig: 4.2.2)

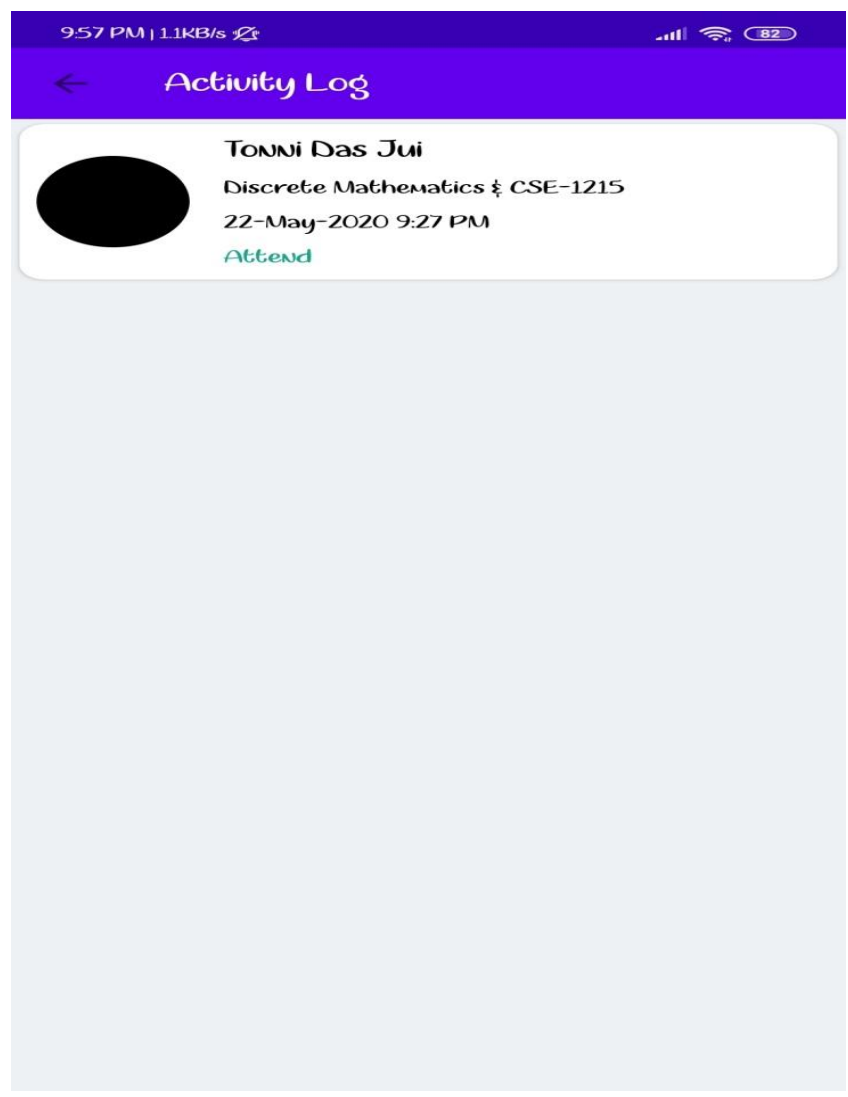

Fig 4.2.4 Student Activity Log Details
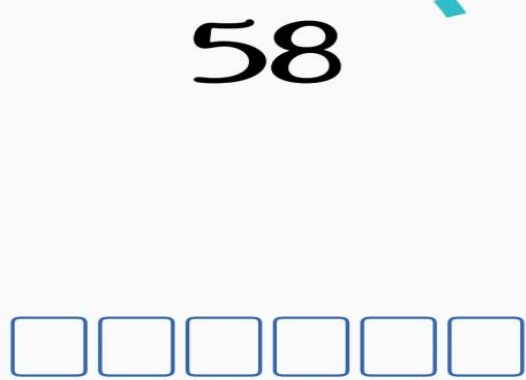

Please type OTP Number before time up.

Fig: 4.2.5 Popup OTP Activity
This is a popup OTP activity. When teacher/lecturer provides a onetime password then the students will input the OTP here. A gsm module could be used for instant location finding purpose which could give better synchronization [10].

\section{CONCLUSION}

Attendance is a very important criterion which is used for various purposes. These purposes included record keeping, consistent attendance in class and all exam attendance during exam periods. The process of recording attendances of students was in form of hard copy and system was manually done. Besides wasting of time and taking efforts of preparing sheets and documents and other disadvantages may be visible to the traditional on due to loss or damage to sheets-sheet could be stolen. On the basis of solving this problem digital attendance system is made. The most important information you need in an attendance is the token number for the attendance. Management of attendance is very helpful in saving students and teachers precious time, writing papers and producing reports at the appropriate time. It is the first version of our project. We have completed our project successfully. However, this just the end of the beginning in that sense that the project can be expanded to a larger dimensions and also the concept can be used for a variety of organization.

\section{ACKNOWLEDGMENTS}

Our thanks to the faculty members of our department who have contributed to conduct the research.

\section{REFERENCES}

[1] S. Rahman, M. rahman, M.M. Rahman, "Automated Student Attendance System using Fingerprint Recognition," Edelweiss Applied Science and Technology, vol. 2, no. 1, pp. 90-94, available at https://www.researchgate.net/publication/324279029_Au tomated_Student_Attendance_System_using_Fingerprint _Recognition, Jan. 2018.

[2] R. Mishra, P. Trivedi, B. Majhi, "Student Attendance System Based On Fingerprint Recognition and One-toMany Matching," Bachelor thesis, Dept. of Computer Science and Engineering, National Institute of Technology, Rourkela-769 008, Orissa, India, 2011.

[3] S. Suryawanshi, P. Jagtap, A. Nadgir, D. Mutha, N Kadam, "Advance Wireless Attendance System Using Fingerprint," International Journal of Innovative Research in Computer and Communication Engineering, vol. 5, no. 3, pp. 2320-9798, Mar. 2017.

[4] B. Soewito, F.L. Gaol, E. Simanjuntak, F.E. Gunawan, "Velocity-Aligned Discrete Oriented Polytopes for Dynamic Collision Detection," IEEE Trans. Visualization 2015 International Conference on Control, Electronics, Renewable Energy and Communications (ICCEREC), Nov 2015, doi: 10.1109/ICCEREC.2015.7337046.

[5] A. Purohit, K. Gaurav, C. Bhati, A. Oak, " Smart attendance," 2017 International conference of Electronics, Communication and Aerospace Technology (ICECA), Apr 2017, doi: 10.1109/ICECA.2017.8203717

[6] O. Oluwadamilola, A. Okubanjo, O. Olaluwoye, " A Secure Students' Attendance Monitoring System," Researchgate, Dec 2015.

[7] F. Alsolami, " iAttend: Secured Fingerprint Attendance System in the Cloud," IJCSNS International Journal of Computer Science and Network Security, vol. 18, no. 11, 
pp.4954,availableathttp://paper.ijcsns.org/07_book/2018 11/20181107.pdf, Nov. 2018.

[8] M.S. Uddin, S.M. Allayear, N.C. Das, and F.A. Talukder, " A Location Based Time and Attendance System," International Journal of Computer Theory and Engineering, vol. 6, no. 1, pp. 49-54, available at https://pdfs.semanticscholar.org/88df/ba6d6da0c7504302 1a4c46904d8d3f0874e9.pdf, Feb. 2014.

[9] S. Dey, S. Barman, R.K. Bhukya, R.K. Das, B.C. Haris, S.R.M. Prasanna and R. Sinha, " Speech Biometric Based Attendance System," Communications (NCC), 2014 Twentieth National Conference, doi: 10.1109/NCC.2014.6811345, available at http://citeseerx.ist.psu.edu/viewdoc/download?doi=10.1. 1.871.8210\&rep=rep1\&type=pdf, Feb. 2014. (URL for Transaction, journal, or magzine)

[10] K. Okokpujie, E. Noma-Osaghae, S. John, K.A. Grace, I. Okokpujie, " A Face Recognition Attendance System with GSM," 2017 IEEE 3rd International Conference on
Electro-Technology for National Development (NIGERCON), vol. 6, no. 1, pp. 239-2444, available at https://core.ac.uk/download/pdf/154229872.pdf, Feb. 2014.

[11] M.S. Uddin, S.M. Allayear, N.C. Das, and F.A. Talukder, "A smart, location based time and attendance tracking system using android application," International Journal of Computer Science, Engineering and Information Technology (IJCSEIT), vol. 5, no. 1, available at http://airccse.org/journal/ijcseit/papers/5115ijcseit01.pdf, Feb. 2015.

[12] H.D. Rjeib, N.S.Ali, A.A. Farawn, B. Al-Sadawi, H. Alsharqi, "Attendance and Information System using RFID and Web-Based Application for Academic Sector," (IJACSA) International Journal of Advanced Computer Science and Applications), vol. 9, no. 1, availableathttps://thesai.org/Downloads/Volume9No1/Pa per_37Attendance_and_Information_System_Using_RFI D.pdf, Feb. 2019. 